\title{
ELECTROCHEMICAL AND SPECTROSCOPIC PROPERTIES OF INDOLIZINO[1,2-B] QUINOLE DERIVATES
}

\author{
$M^{a}$ JOSÉ ALCALDE, LEONARD MOLERO ${ }^{1}$, ALVARO CANETEE ${ }^{1}$, RODRIGO DEL RÍO ${ }^{1}, M^{a}$ ANGÉLICA DEL \\ VALLE', RICARDO MALLAVIA' AND FRANCISCO ARMIJO ${ }^{2}$ \\ ${ }^{1}$ Departamento de Química Inorgánica, Facultad de Química, Pontificia Universidad Católica de Chile, \\ Av. Vicuña Mackenna 4860, Casilla 306, Correo 22, Santiago, Chile. \\ ${ }^{2}$ Instituto de Biología Molecular y Celular, Universidad Miguel Hernandez de Elche, Avda. de la Universidad s/n, 03202 Elche, Spain. \\ (Received: June 18, 2013 - Accepted: September 16, 2013)
}

\begin{abstract}
A series of indolizino[1,2-b] quinole derivates compounds were characterized by various electrochemical and spectroscopic techniques. Electrochemical studies reveal that there are two redox processes controlled by diffusion, the first step corresponds to the formation of a semiquinone radical $\mathrm{Q}^{-}$, while the second step corresponds to the formation of quinone dianion, $\mathrm{Q}^{2-}$. The presence of acceptor groups such as - $\mathrm{CN}$ and -COOH shifted reduction potentials, due to a more favorable electronic stabilization. There was no significant effect of the substituents on the absorption spectra of indolizino[1,2-b] quinole derivates. The substituents influenced the fluorescence properties from indolizino[1,2-b] quinole derivates. The emission and excitation spectra obtained of these compounds suggested that the molecule emits from a locally excited state having identical geometry with that of ground state geometry. Finally it was observed that the group with higher acceptor capacity $(-\mathrm{CN})$, has the highest quantum yield, which is indicating that this group always stabilized electronic state with a higher conjugation.
\end{abstract}

Keywords: Indolequinone, Quinone, Electrochemical Characterization, Optical Absorption; Fluorescence Emission

\section{INTRODUCTION}

Quinones are systems that are presents in some natural and synthetic compounds; they are an important biologically active agent from coenzyme Q, vitamin $\mathrm{K}$ to anticancer antibiotics doxorubicin ${ }^{1}$. The biological mode of action of quinones is dependent on their structure, and they can act as covalent modifiers of biomolecules, DNA intercalators, and/or generators of reactive oxygen species through redox cycling. The reduction of quinones by enzymes involucres at least two process: through a one electron pathway to produce semiquinone radicals by reductive enzymes like CYP450 reductase, cytochrome $b_{5}$ reductase and ubiquinone oxireductase, or through a two electron pathway to hydroquinones by reductive enzymes like DT-diaphorase ${ }^{2}$.

Electrosynthesis and electrochemical techniques can be applied in the analysis of synthetic and natural products and provide information about the bioactive properties of the studied systems or compounds, mainly those related to their antitumoral and antiparasitic activity. Also, they try to provide an electrochemical description of the bioactive compounds that possess in their structure appropriate functional groups, enabling electronic transfer (ET) modulation. However, the obtained electrochemical parameters usually show poor correlation with biological activity, due to the enormous complexity of biomedical chemistry. Indeed, in a live host, this kind of relationship is always complex, usually dominated by many factors. So, these correlations should be carefully interpreted. Among the various factors, the modus operandi of the compound in terms of its activity in vivo should be considered. Examples: stereochemistry, diffusion, solubility, metabolism, permeability in the membrane, and so on ${ }^{3}$. We must also consider other factors such as bioavailability, partition coefficient, and specific interactions, because they also play an important role. Many physiological processes are based on the oxidation-reduction chain involved in successive processes catalyzed by different enzymes. If ET steps are compared, there exist a number of similarities between the biological and electrochemical reactions that cannot be replicated by other chemical systems ${ }^{4}$. As an approach to biomedical chemistry, electrochemistry has been generally used in processes where in bio-oxidations and bio-reductions are involved, and may be used as an analytical tool, or to predict biological phenomena ${ }^{5,6}$ Therefore, preliminary electrochemical studies should generate a great amount of information regarding TE processes in biological processes. In this context, electrochemical techniques have been used to elucidate the mechanism of action of some bioactive compounds. For this purpose electrochemical devices and spectroscopic methods are coupled, allowing a redox system study in aprotic and aqueous media, as well as to evaluate the behavior of free radicals generated in biological systems.

Our interest in quinones is focused on structure-activity relationship of series Indolizino [1,2-b]quinolin derivatives (Figure 1). Furthermore, structure activation relationship (SAR) studies for quinone system showed that pharmacokinetic properties are due to presence or absences of groups in position 2, 3 and 5 according a SAR of indolequinones models. According of this idea, an aziridinyl group at 5 positions plays an important role above selectivity and potency to design anticancer prodrugs. In another hand, the presence of electro withdrawing group in 3 position and heteroatom groups in 2 positions is also important to cancer selectivity ${ }^{2,7}$.

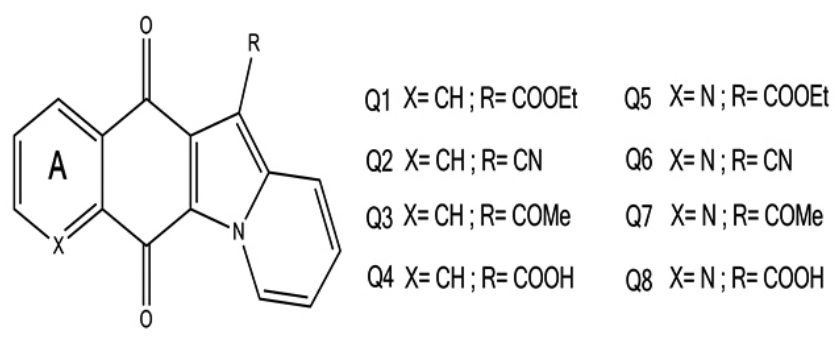

Figure 1. Structures of Indolizino[1,2-b]quinolin derivatives.

\section{EXPERIMENTAL}

Materials

All chemicals used in this work were of analytical grade, Sigma-Aldrich and used without further purification. The monomer was 1-amino-9,10-anthraquinone (AAQ), and the supporting electrolyte used for electrochemical experiments was tetrabutylammonium hexafluorophosphate $\left(\mathrm{TBAPF}_{6}\right) 0.1 \mathrm{~mol} \cdot \mathrm{L}^{-1}$ for electrochemical analysis, $\geq 99.0 \%$ in acetonitrile anhydrous (ACN), $99.8 \%$. Prior to each experiment the solution was deoxygenated by flushing with argon ( $99.99 \%$ ) for $20 \mathrm{~min}$. All experiments were conducted at room temperature (20 $\left.{ }^{\circ} \mathrm{C}\right)$, under argon atmosphere.

Synthesis of indolizino[1,2-b] quinole derivates

The quinoline's compounds Q1-Q8, were synthesized accord to reference

Electrochemical investigations

Electrochemical measurements were performed on a $\mathrm{CHI}$ Instruments Model 900B potentiostat using a conventional three-electrode cell. Platinum and platinum wires were used as working and counter electrode, respectively. All potentials quoted in this work are refered to an $\mathrm{Ag} / \mathrm{AgCl}, \mathrm{KCl}$ (sat'd) reference electrode (0.197 V vs NHE).

$U V$-visible and Fluorescence spectroscopic

UV-visible absorption spectra were registered on a Specord 40 Spectrophotometer (Analytik Jena). All recorded spectra were baseline corrected. Steady state fluorescence spectra were recorded on a spectrofluorimeter (Photon Technology International model C-60). Data acquisition was processing with FeliX32 software. For fluorescence quantum yield measurements, the solutions of compounds Q1-Q8 in acetonitrile were optically matched at the 
excitation wavelength $(488 \mathrm{~nm})$, and then the quantum yield was calculated by comparing the integrated areas under the emission curves. Rhodamine $6 \mathrm{G}$ in $0.1 \mathrm{~mol} \cdot \mathrm{L}^{-1}$ ethanol (UVASOL, Merck) $\left(F_{\mathrm{f}}=0.95\right)$ was used as reference ${ }^{8}$. The measured $F_{\mathrm{f}}$ values are accurate within $\pm 10 \%$.

\section{RESULTS AND DISCUSSION}

Electrochemical characterization

The electrochemical characterization of the indolizino[1,2-b] quinole derivates to $1 \cdot 10^{-3} \mathrm{~mol} \cdot \mathrm{L}^{-1}(\mathrm{Q} 1-\mathrm{Q} 8)$, was performed by means of cyclic voltammetry (CV) in ACN as a solvent (Figure 2), using a three-electrode cell as that described in the experimental part.
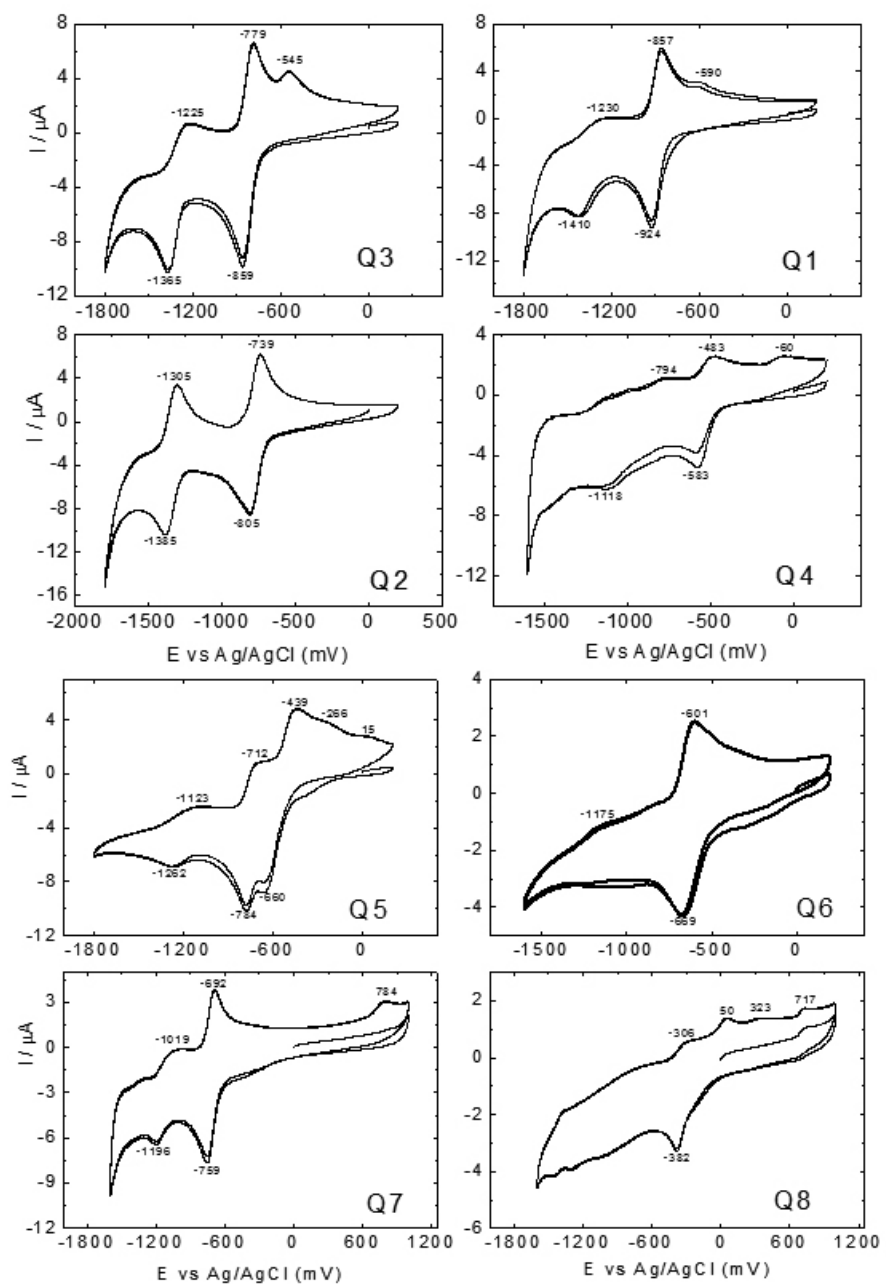

Figure 2. Comparative electrochemical responses of selected compounds in $\mathrm{ACN} v s \mathrm{Ag} / \mathrm{AgCl}$ at scan rate, $v=100 \mathrm{mV} \cdot \mathrm{s}^{-1}$.

Quinones generally may be found in three redox states: the oxidized state or quinone as radical semiquinone and reduced state or hydroquinone ${ }^{9,10,11}$. Sarathi et al. described in a review, in nonaqueous media, the reductions of quinones $(\mathrm{Q})$ take place by two successive one-electron reduction steps generating two separate cathodic waves, in which the first step is completely reversible and the second step is quasi-reversible at customary scan rates ${ }^{12}$. Voltammetric studies of Q1 to Q8 at different scan rates to show current peaks of first and second reduction waves are proportional to square root of the scan rate, indicating a diffusion controlled process. Figure 3 shows redox processes AAQ. This molecule was used as a reference to determine the redox potential corresponding to the first step corresponds to the formation of a semiquinone radical $\mathrm{Q}^{--}$while the second step corresponds to the formation of quinone dianion, $\mathrm{Q}^{2-}$.

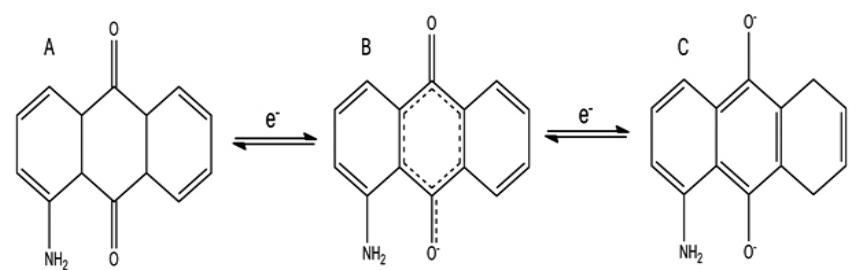

Figura 3. Electronic transfer processes of AAQ: A. Quinone state; B. Semiquinone radical state; C. Quinone dianion state

Table 1 summarizes the redox potential data of all investigated compounds. The resulting $\Delta \mathrm{Ep}=66-100 \mathrm{mV}$ for Q1-Q4 and Q5-Q8 $\Delta \mathrm{Ep}=67-76 \mathrm{mV}$ determine the reversibility of processes for the first redox couple (Q*), indicating that the process is reversible. The presence of azilridinyl groups at $\mathbf{A}$ ring (Fig. 1 ) and the presence of a group $\mathbf{R}$ with higher acceptor behavior $(-\mathrm{CN})$, show redox process with better reversibility. The $\Delta \mathrm{Ep}$ values for the second redox couple $\left(\mathrm{Q}^{2-}\right)$ increased indicating that this process is quasi-reversible.

When comparing the formal potential $\mathbf{E}^{\mathbf{o}^{\prime}}$ for Q1-Q4, the following order for the first redox process is obtained: $\mathrm{Q} 4<\mathrm{Q} 2<\mathrm{Q} 3<\mathrm{Q} 1$. If the $\mathbf{R}$ group has greater acceptor behavior, a shift towards lower reduction potential occurs, meaning that groups such as $-\mathrm{COOH}$ and $-\mathrm{CN}$ help the formation of the semiquinone radical species $\mathrm{Q}^{--}$.

Table 1. Characterization data for indolizino[1,2-b] quinole derivates under study: cyclic voltammetry data obtained from voltammograms ( $v s \mathrm{Ag}$ / $\mathrm{AgCl}$ ) of compounds Q1-Q8 in ACN /1.0 mM TBAPF 6 (supporting electrolyte $)$ at a scan rate of $100 \mathrm{mV} \cdot \mathrm{s}^{-1} \cdot \mathrm{E}^{\mathrm{o}}=\left(\mathrm{E}_{\mathrm{pc}}-\mathrm{E}_{\mathrm{pa}} / 2\right), \Delta \mathrm{E}_{\mathrm{p}}\left(=\mathrm{E}_{\mathrm{pc}}-\mathrm{E}_{\mathrm{pa}}\right), \mathrm{I}_{\mathrm{pc}} / \mathrm{I}_{\mathrm{pa}}($ ratio between cathodic and anodic peak current)

\begin{tabular}{|c|c|c|c|c|c|c|}
\hline \multirow[b]{2}{*}{$\mathbf{Q}$} & \multicolumn{2}{|c|}{$\begin{array}{l}\text { Semiquinone } \\
\text { radical }\end{array}$} & \multicolumn{2}{|c|}{ Quinone dianion } & \multicolumn{2}{|c|}{$\mathbf{E}^{\mathbf{o}^{\prime}}=\left(\mathbf{E}_{\mathrm{pa}}+\mathbf{E}_{\mathrm{pc}} / 2\right)^{\mathrm{a}}$} \\
\hline & $\begin{array}{l}\mathrm{E}_{\mathrm{pa}} \mathrm{I} \\
(\mathrm{mV})\end{array}$ & $\begin{array}{l}E_{\mathrm{pc}} \mathbf{V} \\
(\mathrm{mV})\end{array}$ & $\begin{array}{l}\mathbf{E}_{\mathrm{pa}} \mathrm{II} \\
(\mathrm{mV})\end{array}$ & $\begin{array}{c}\mathbf{E}_{\mathrm{pc}} \mathbf{I I} \\
(\mathbf{m V})\end{array}$ & $\begin{array}{c}\mathbf{E}^{0} \mathbf{I} \\
(\mathbf{m V})\end{array}$ & $\begin{array}{l}\mathbf{E}^{0} \mathrm{II} \\
(\mathrm{mV})\end{array}$ \\
\hline AAQ & -1087 & -992 & -1520 & -1442 & -1040 & -1481 \\
\hline Q1 & -857 & -924 & -1230 & -1410 & -891 & -1320 \\
\hline Q2 & -739 & -805 & -1305 & -1385 & -772 & -1345 \\
\hline Q3 & -779 & -859 & -1225 & -1365 & -819 & -1295 \\
\hline Q4 & -483 & -583 & -794 & -1118 & -533 & -956 \\
\hline Q5 & -712 & -784 & -1123 & -1262 & -748 & -1193 \\
\hline Q6 & -601 & -669 & -1175 & - & -635 & - \\
\hline Q7 & -692 & -759 & -1019 & -1196 & -726 & -1108 \\
\hline \multirow[t]{2}{*}{ Q8 } & -306 & -382 & - & - & -344 & - \\
\hline & \multicolumn{4}{|c|}{$\Delta E_{p}\left(=E_{p c}-E_{p a}\right)$} & \multicolumn{2}{|c|}{$\Delta \mathbf{E}_{\mathrm{p}}\left(=\mathbf{E}_{\mathrm{pc}}-\mathbf{E}_{\mathrm{pa}}\right)$} \\
\hline$Q$ & $\Delta E p I$ & \multicolumn{3}{|l|}{$-I p a_{1} / I p c_{1}$} & $\Delta E p$ II & $-I p a_{2} / I p c_{2}$ \\
\hline AAQ & 95 & \multicolumn{3}{|l|}{0.460} & 78 & 0.730 \\
\hline Q1 & 67 & \multicolumn{3}{|l|}{0.660} & 180 & 0.032 \\
\hline Q2 & 66 & \multicolumn{3}{|l|}{0.720} & 80 & 0.330 \\
\hline Q3 & 80 & \multicolumn{3}{|l|}{0.670} & 140 & 0.075 \\
\hline Q4 & 100 & \multicolumn{3}{|l|}{0.550} & 324 & 0.210 \\
\hline Q5 & 72 & \multicolumn{3}{|l|}{0.085} & 139 & 0.350 \\
\hline Q6 & 68 & \multicolumn{3}{|l|}{0.570} & - & - \\
\hline Q7 & 67 & 0.510 & & & 177 & 0.0045 \\
\hline Q8 & 76 & 0.170 & & & - & - \\
\hline
\end{tabular}

a .- Formal reduction potentials $\left(E^{0} I^{\prime}\right.$ and $\left.E^{0} I I\right)$ for each quinone were determined, Epa and Epc refer to the anodic and cathodic peak potentials. 
The order for $\mathbf{E}^{\mathbf{o}^{\prime}}$ of the second redox process was: Q4 $<$ Q3 $<$ Q1 $<$ Q2, showing that the presence of the $-\mathrm{COOH}$ group also favors the formation of quinone dianion $\mathrm{Q}^{2-}$.

It has been reported that the presence of these groups stabilize via an additional intramolecular hydrogen bond, resulting in two 6-member chelate rings. As a consequence of this, an electron symmetry for the whole molecule arises, which leads to stabilization of the two carbonyl groups ${ }^{13,14,15}$.

Q5-Q8 quinones exhibit the same behavior when comparing the formal potentials of both redox couples. Moreover, the presence of the group $\mathrm{X}=$ $\mathrm{N}$ in the ring A (Fig.1), with the same substituent group show formal redox potentials for these molecules shifting to lower potentials. Thus, to have quinones with lower redox formal potential, required less energy to generate their anionic radical and dianion reduced states.

\section{Absorption spectroscopy}

Figure 4 shows electronic absorption spectra of the indolizino[1,2-b] quinole derivates recorded in $\mathrm{ACN}$ solvent.

As reference, molecule AAQ was used to assign the electronic transition bands of Q1-Q8 (table 2 shows the results). In the UV-Visible spectrum of AAQ it can be observed (data not shown) a first $244 \mathrm{~nm}$ absorption band corresponding to $\pi-\pi^{*}$ benzenoid transition band, a second one at $272 \mathrm{~nm}$ and a third absorption band at $309 \mathrm{~nm}$, the latter two corresponding to $\pi$ - $\pi^{*}$ quinonoid transition bands, and finally an absorption band near $470 \mathrm{~nm}$ corresponding to a $\eta-\pi^{*}$ quinonoid transition band ${ }^{9}$.


Figure 4. Comparative UV-visible spectra of selected indolizino[1,2-b] quinole derivates compounds in ACN.

Table 2. Comparison of absorption bands and molar absorptivity of indolizino[1,2-b] quinole derivates.

\begin{tabular}{|c|c|c|c|c|c|}
\hline \multirow{2}{*}{$Q$} & Benzenoid & Quinonoid & Quinonoid & Benzenoid & Quinonoid \\
\hline & $\pi-\pi *\left(\mathrm{e} / \mathrm{M} \cdot \mathrm{cm}^{-1}\right)$ & $\pi-\pi *\left(\mathrm{e} / \mathrm{M} \cdot \mathrm{cm}^{-1}\right)$ & $\pi-\pi *\left(\mathrm{e} / \mathrm{M} \cdot \mathrm{cm}^{-1}\right)$ & $\pi-\pi *\left(\mathrm{e} / \mathrm{M} \cdot \mathrm{cm}^{-1}\right)$ & $\nu-\pi *\left(\mathrm{e} / \mathrm{M} \cdot \mathrm{cm}^{-1}\right)$ \\
\hline$A A Q$ & $244(36529)$ & $272(12768)$ & $309(5110)$ & - & $470(6833)$ \\
\hline$Q 1$ & $257(7850)$ & $287(2544)$ & $320(2225)$ & $352(1214)$ & $466(1083)$ \\
\hline$Q 2$ & $257(37845)$ & $288(13152)$ & $322(11480)$ & $350(6812)$ & $462(4901)$ \\
\hline$Q 3$ & 261(7534) & $276(4594)$ & $326(2448)$ & $358(1416)$ & $475(1142)$ \\
\hline$Q 4$ & $247(20115)$ & - & - & - & $550(3562)$ \\
\hline$Q 5$ & 251(38197) & - & $325(12267)$ & $355(8072)$ & $469(6977)$ \\
\hline Q6 & $250(18890)$ & - & $322(5270)$ & $354(3381)$ & $468(2554)$ \\
\hline$Q 7$ & $250(24736)$ & 261(24113) & $329(7480)$ & $360(4934)$ & $480(4158)$ \\
\hline$Q 8$ & $242(7833)$ & $269(4554)$ & $310(1874)$ & $360(489)$ & $520(1419)$ \\
\hline
\end{tabular}

Quinone's studies show that these compounds exhibit intense absorption bands in the range of 250-300 $\mathrm{nm}$ and weaker overlapping bands in the region of $330-400 \mathrm{~nm}$ due to quinonoid and benzenoid $\pi \rightarrow \pi^{*}$; ; substituent - $\mathrm{COOH}$ group affects quinonoid $\eta-\pi^{*}$ transitions, which is influenced by the acid-base balance. When Q4 spectra performed in water at $\mathrm{pH}$ around 7, or in a basic medium the absorption band shifts to longer wavelengths (data not shown). The absorption bands of substituted quinone when compared with the unsubstituted quinone, distinctly shift to shorter or longer wavelengths according to the substituting group. When quinone is substituted with electron donating group $\left(-\mathrm{OH},-\mathrm{NH}_{2}\right.$, etc.) there will be an absorption band longer than $350 \mathrm{~nm}$. Moreover, the increase of electron donating ability of the substituents leads the shift to bathochromic region ${ }^{16,17}$. The indolequinones Q4 and Q8, which have a substituent $-\mathrm{COOH}$ exhibit this behavior.

Generally, the substituents - $\mathrm{CN}$, - $\mathrm{COMe}$ and -COOEt no change the obtained UV-visible spectrum, because they are very similar. When comparing e values $\left(\mathrm{M}^{-1} \cdot \mathrm{cm}^{-1}\right)$ of indolquinones Q1, Q2, Q3 and Q4, if withdrawing groups (such as $-\mathrm{COOH}$ and $-\mathrm{CN}$ ) are present in the molecule, there is an increase of the molar absorptivity. This may be because these groups stabilize an electronic state more conjugated, withdrawing groups such as -COMe and -COOEt are not able to stabilize this state showing lower molar absorptivity values. In return, the presence of azilridinyl groups at $\mathbf{A}$ ring (Fig. 1) shows the opposite effect: compounds with substituent groups -COMe and -COOEt have higher molar absorptivity. This should be attributed to more capable acceptor groups and the group azilridinyl conjugation affect the excited electronic state, decreasing the molar absorptivity.

\section{Fluorescence}

Strongly absorbing samples were diluted in ACN, at concentrations suitable for optical density of the samples did not exceed the range of absorbance values of 0.05 to avoid inner filter effects. The fluorescence emission profile of selected indolizino[1,2-b] quinole derivates was recorded in $\mathrm{ACN}$ solvent. Figure 5 shows the fluorescence spectra obtained at a wavelength of excitation $\lambda_{\text {exc }}=460 \mathrm{~nm}$ for indole quinones Q1, Q2, Q3, Q6 and Q8, respectively. We note that the indole quinone having in its structure the - $\mathrm{COOH}$ group is the only one that will not fluoresce. It has been reported in other studies where the - $\mathrm{COOH}$ group can form non-planar structures in solution, producing a fluorescence quenching ${ }^{18}$.

The emission and excitation spectra obtained for these compounds (data not shown) suggested that the molecule emits from a locally excited (LE) state having identical geometry with that of ground state geometry ${ }^{19}$. On the other hand, a relatively less structured, single fluorescence emission band was observed for indolizino[1,2-b] quinole derivates having the emission maxima between 553 and $570 \mathrm{~nm}$. These fluorescence emission bands were more redshifted with respect to the corresponding absorption spectra, indicating the influence of extended conjugation on singlet state (S1). The quantum yields are collected in Table 3 . 


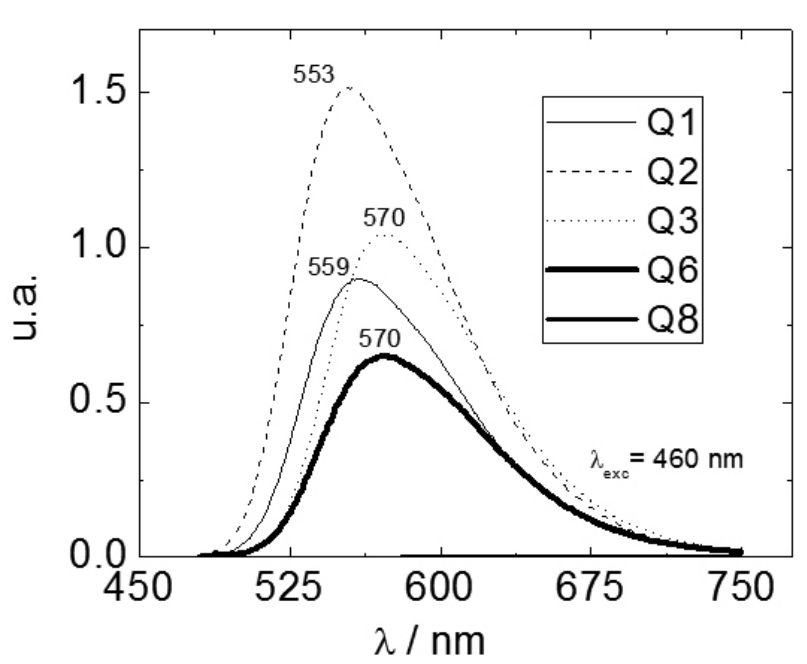

Figure 5. Comparative fluorescence spectra of selected indolizino[1,2-b] quinole derivates compounds in ACN.

Tabla 3. Quantum yield for the various indolizino[1,2-b] quinole derivates compounds.

\begin{tabular}{|c|c|c|c|c|c|c|}
\hline $\mathbf{Q}$ & $\mathbf{Q 1}$ & $\mathbf{Q 2}$ & $\mathbf{Q 3}$ & $\mathbf{Q 6}$ & $\mathbf{Q 7}$ & Q5 \\
\hline$\phi_{\mathrm{m}}$ & 0.261 & 0.408 & 0.191 & 0.149 & 0.060 & 0.071 \\
\hline
\end{tabular}

From Table 3 it was observed that, the change in the emission intensity as well as the quantum yields in indolizino[1,2-b] quinole derivates compounds may be due to the change in the electronic structure of the azilridinyl groups at A ring. The decrease is three times lower when comparing the quantum yield between the molecules Q1/Q5, Q2/Q6 and Q3/Q5. Finally, it is observed that the group with higher acceptor capacity $(-\mathrm{CN})$, has the highest quantum yield, which is indicating that this group always stabilized electronic state with a higher conjugation.

\section{CONCLUSIONS}

A series of indolizino[1,2-b] quinole derivates compounds were characterized by various electrochemical and spectroscopic techniques. Electrochemical studies reveal that there are two redox processes controlled by diffusion: the first step corresponds to the formation of a semiquinone radical $\mathrm{Q}^{--}$while the second step corresponds to the formation of quinone dianion, $\mathrm{Q}^{2-}$. The presence of acceptor groups, such as $-\mathrm{CN}$ and $-\mathrm{COOH}$, shifted the reduction potentials of semiquinone radical and quinone dianion formation, due to a more favorable electronic stabilization. There was no significant effect of the substituents on the absorption spectra of indolizino[1,2-b] quinole derivates, but the substituents influenced the fluorescence properties of indolizino[1,2-b] quinole derivates. The emission and excitation spectra obtained for these compounds suggested that the molecule emits from a locally excited (LE) state having identical geometry with that of ground state geometry. Finally, it is observed that the group with higher acceptor capacity $(-\mathrm{CN})$ has the highest quantum yield, which indicating that this group always stabilize the electronic state with a higher conjugation.

\section{ACKNOWLEDGEMENTS}

This research was financially supported by Fondecyt (Chile), Project 1110041.

\section{Dedication}

This work is dedicated to Dr. Elsa Abuin (RIP), to whom we express our admiration and respect, not only as a great scientist, but especially for her outstanding human qualities.

\section{REFERENCES}

1. K. A. Werbovetz, Curr. Med. Chem. 7, 835, (2000).

2. Y. Chen, L. Hu, Med. Res. Rev. 29, 29, (2009).

3. K. R. Kunz, B. S. Iyengar, R. T. Dorr, D. S. Alberts, W. A. Remers, J. Med. Chem. 34, 2281, (1991).

4. G. Dryhurst in Electrochemistry of Biological Molecules; Academic Press; New York, 1977, chapter 1, pp.1-5.

5. T. J. Monks, R. P. Hanzlik, G. M. Cohen, D. Ross, D. G. Graham, Toxicol. Appl. Pharmacol. 112, 2 (1992).

6. M. O. F. Goulart, C. L. Zani, J. Tonholo, L. R. Freitas, F. C. de Abreu, A. B. Oliveira, D. S. Raslan, S. Starling, E. Chiari, Bioorg. Med. Chem. Lett. 7, 2043 (1997).

7. A. Cañete, F. Armijo, M. A. del Valle, R. Tapia, C. Teodopulus, C. D. Pessoa, G. Recabarren, J. Chil. Chem. Soc. 57, 1126, (2012).

8. R. F. Kubin, A. N. Fletcher, J. Luminesc. 27, 455, (1982).

9. R. M Cory, D. M. McKnight, Environm. Sci. Technol. 39, 8142, (2005).

10. J. Tonholo, L. R. Freitas, F.C. de Abreu, D. C. Azevedo, C. L. Zani, A. B. de Oliveira, M. O. F. Goulart, J. Braz. Chem. Soc. 9, 163, (1998).

11. N. Muthukumar, A. Ilangovan, S. Maruthamuthu, N. Palaniswamy, Electrochim. Acta 52, 7183 (2007).

12. P. S. Guin, S. Das, P. C. Mandal, Int. J. Electrochem. 2011, 22 pages (2011), Article ID 816202.

13. T. Philipovaa, C. Ivanova, Y. Kamdzhilov, M. T. Molina, Dyes and Pigments 53, 219 (2002).

14. V. Sasirekha, P. Vanelle, T. Terme, V. Ramakrishnan, Spectrochim. Acta Part $A$ 71, 766 (2008).

15. P. Dahiya, D. K. Maity, S. K. Nayak, T. Mukherjee, H. Pal, J. Photochem. Photobiol. A: Chem. 186, 218 (2007).

16. V. Sasirekha, P. Vanelle, T. Terme, V. Ramakrishnan, J. Fluoresc. 19, 419, (2009).

17. M. S. Khan, Z. H. Khan, Spectrochim. Acta Part A 61, 777, (2005).

18. P. Dahiya, S. Dutta Choudhury, D. K. Maity, T. Mukherjee, H. Pal, Spectrochim. Acta Part A 69, 134 (2008).

19. C. K. Kumar, R. Trivedi, K. R. Kumar, L. Giribabu, B. Sridhar, J. Organomet. Chem. 718, 64 (2012). 